\title{
Women in Saudi Arabia and the Prevalence of Cardiovascular Risk Factors: A Systematic Review
}

\author{
Mashael K. Alshaikh, ${ }^{1,2}$ Filippos T. Filippidis, ${ }^{1}$ Juren P. Baldove, ${ }^{3}$ \\ Azeem Majeed, ${ }^{1}$ and Salman Rawaf ${ }^{1}$ \\ ${ }^{1}$ Department of Primary Care and Public Health, School of Public Health, Faculty of Medicine, Imperial College London, London, UK \\ ${ }^{2}$ Department of Pharmacy, King Saud University Medical City, Riyadh, Saudi Arabia \\ ${ }^{3}$ Department of Critical Care, King Saud University Medical City, Riyadh, Saudi Arabia
}

Correspondence should be addressed to Mashael K. Alshaikh; m.alshaikh14@imperial.ac.uk

Received 9 May 2016; Revised 9 August 2016; Accepted 23 August 2016

Academic Editor: Stephen Leeder

Copyright (C) 2016 Mashael K. Alshaikh et al. This is an open access article distributed under the Creative Commons Attribution License, which permits unrestricted use, distribution, and reproduction in any medium, provided the original work is properly cited.

\begin{abstract}
Background. Cardiovascular disease (CVD) is one of the leading causes of death in Saudi Arabia. Saudi women in particular are more susceptible as there are sociocultural restrictions on female physical activities that may lead to high prevalence of CVD risks, especially obesity, and physical inactivity. This study aims to systematically review the published articles related to the prevalence of CVD risk among women in Saudi Arabia. The search strategy covers all published articles that assess the risk factor of CVD in Saudi Arabia from January 2000 to December 2015, using the following sources: Medline, Embase, and PsycINFO. A total of 61 studies were included. Results. Prevalence among Saudi women of smoking ranged from 1.1\% to 9.1\%, hypertension was $21.8 \%$, diabetes ranged from $9.6 \%$ to $27.6 \%$, overweight was $27 \%$, and obesity was $40.23 \%$, and physical inactivity ranged from $53.2 \%$ to $98.1 \%$. Hypercholesterolemia prevalence on Saudi women on average was $24.5 \%$, while metabolic syndrome ranged from $13.6 \%$ to 40.3\%. Conclusion. The prevalence of CVD risk factors is high among women in Saudi Arabia especially in obesity and physical inactivity. Public health authorities must implement solutions from a gender specific aspect to reverse the trend and decrease the prevalence of CVDs among Saudi women.
\end{abstract}

\section{Introduction}

Cardiovascular disease (CVD) is a major public health problem, and one of the main causes of death globally [1]. According to the World Health Organization (WHO) in 2011, CVD accounted for 17.3 million deaths per year, and by 2030 this number is expected to grow to more than 23.6 million $[1,2]$.

There are a number of established measurable risk factors, for example, diabetes, hypertension, and obesity that may lead to the development of CVD events. These risk factors are aspects of a patient's style of living that can be modified. Knowing the risk factors is a useful approach for identifying people at high risk who will most benefit from counselling and clinical management of their risk factors [3]. In recent years, age-adjusted CVD mortality has been cut in half in developed countries due to a decrease in associated risk factors [4]. Therefore, focusing on reducing risk factors is a major improvement in terms of developing strategies for preventing CVD [5], and this can explain the decline in CVD mortality and morbidity [6].

The WHO has developed specific strategies to have a paradigm shift from CVD treatment to CVD prevention; this approach is recommended for CVD prevention worldwide [5]. Effective, integrated health promotion policies and programmes are one of the best tools to counteract the epidemic of obesity, diabetes, and other CVD risks that are emerging worldwide [7]. Applying these recommendations helps to shift the focus towards the prevention of primary risk factors, and in the long term it can lead to health improvement and decrease CVD [4].

However, in the Arab Gulf region, around 50\% of the deaths of those aged below 70 were found to be attributed to CVD deaths, while in Western countries (UK, Germany 
"Cardiovascular risk factors" OR "coronary heart disease risk factors" OR "stroke risk factors"

OR "diabetes mellitus" OR "epidemiology of diabetes mellitus" OR "NIDDM" OR "dyslipidaemia"

OR "epidemiology of dyslipidaemia" OR "hypercholesterolemia” OR "high cholesterol”

OR "smoking" OR "tobacco use" OR "epidemiology of smoking" OR "hypertension"

OR "high blood pressure" OR "epidemiology of hypertension" OR "obesity" OR "overweight" OR "BMI"

OR "epidemiology of obesity" OR "physical activity" OR "exercise" OR "epidemiology of physical activity"

OR "Metabolic Syndrome X" OR "Metabolic syndrome” AND "Saudi Arabia”

Box 1: Selected search terms.

and the US), it is about 25\%, a dramatic difference [8]. This is particularly true for CVD deaths from ischemic heart disease, obesity, and diabetes complications $[9,10]$. In 2008, there were more than one million deaths in Arab countries from noncommunicable diseases, which accounted for $60 \%$ of all deaths [11]. Aljefree and Ahmed conducted a systematic review on the prevalence of CVD and its associated risk factors among the adult population in the Gulf region, and they concluded that there was a high prevalence of CVD risks in Gulf countries, particularly regarding obesity among women in this region [12].

Saudi Arabia is the largest country on the Arabian Peninsula, extending over an area of $2,150,000 \mathrm{~km}^{2}$, with a population of more than 30 million [13]. It is one of the rapidly developing countries, adapting an increasingly urbanised lifestyle [14]. The country has reported an increase in CVDs parallel to that of other rapidly developing economies. The most predominant CVD risk factors include diabetes mellitus, obesity, hypertension, sedentary lifestyle, and smoking. The increasing prevalence of these risk factors has led to a growing incidence of ischaemic heart disease and heart failure [15]. The Saudi Project for Assessment of Coronary Events (SPACE) Registry, the first registry in Saudi Arabia that investigates patients with acute coronary syndrome (ACS), found that more than half of the patients admitted with ACS had diabetes, and around half were having hypertension. They also found that patients diagnosed with ACS in Saudi Arabia are 8 to 11 years younger than the homologous patients in ACS registries found in developed countries [16].

Women in Saudi Arabia are not allowed to drive, and they are required to have a guardian for transportation purposes [17]. Furthermore, there is no sports education in girls' schools and it is prohibited by social norms for females to practice physical activities in public schools [18]. All of these sociocultural factors have created unhealthy lifestyles, which have become part of the social norms within Saudi society, thereby increasing the prevalence of sedentary lifestyle and obesity in women living in Saudi Arabia [19].

This paper aims to review the published works related to the prevalence of CVD risk among women in Saudi Arabia. Cardiovascular disease affects many women in Saudi Arabia, and for this reason, it is important to decrease the burden of the risk and to identify the most dominant factors among women in Saudi Arabia. Until now, there has been no systematic review, studying the prevalence of CVD risk among adult women in different regions and populations, for example, among university students, those attending primary care clinics and from the national studies in Saudi Arabia.

\section{Methods}

2.1. Review Question. A literature exploration was used to identify relevant published studies of prevalence of CVD risk factors, in order to answer the following question: what is the prevalence of obesity, diabetes, hypertension, hypercholesterolemia, physical inactivity, and metabolic syndrome among women living in Saudi Arabia?

2.2. Search Strategy. The search strategy intended to cover all published literature written in English and Arabic that look at the risk factors of CVD in Saudi Arabia. The target articles covered the period from January 2000 to December 2015. This period was chosen in order to account for advances both in treatments and in medical technology.

A three-step search strategy was utilized in this review using the following sources: Medline (January 2000 to December 2015); Embase (January 2000 to December 2015); PsycINFO (January 2000 to December 2015). Step 1: the search was undertaken across all the databases using all of the identified keywords. Step 2: the titles and abstracts of all the articles of potential interest were reviewed for the inclusion and exclusion of studies. Step 3: the reference lists of all identified reports and articles were searched for additional relevant studies. We used combinations of medical subject headings (MESH) using the following search terms (see Box 1).

2.3. Selection of Studies. After applying the aforementioned three steps of the search strategy, two reviewers (Mashael K. Alshaikh and Juren P. Baldove) independently screened the titles and abstracts of the initially identified studies to determine whether they would satisfy the selection criteria. Full-text articles were retrieved for the selected titles. The reference lists of the retrieved articles were searched for additional publications.

All studies, wherein body mass index (BMI), obesity, metabolic syndrome, hypertension, dyslipidaemia, and physical inactivity were investigated, were eligible for inclusion. No limitations on publication type, status, or study design were imposed. However, we did not include secondary reports such as review articles without novel data synthesis. The inclusion criteria required that the studies had been 


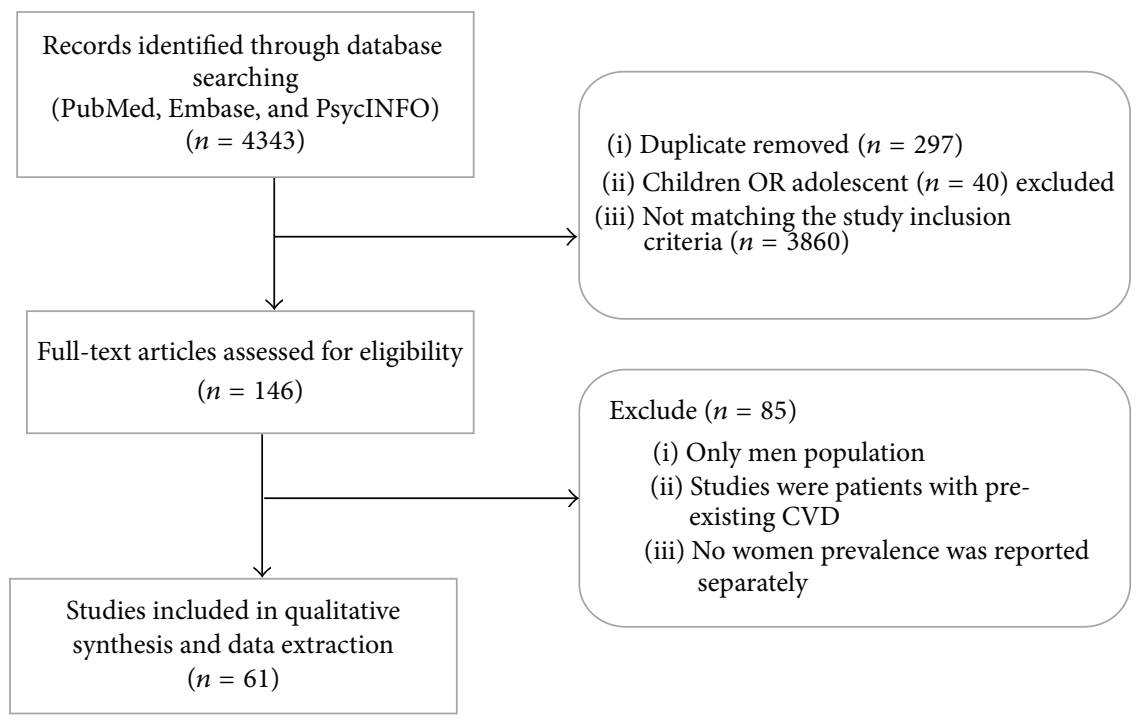

FIGURE 1: Flow chart of study selection.

carried out in Saudi Arabia, and included populations comprised of adults aged above 15 years old; both resident and expatriate populations and urban and rural populations were included. Studies of the general population, those working, students, those attending healthcare, and other populations were included. We did not specify diagnostic criteria for the studied conditions but incorporated them into our data synthesis.

2.4. Data Extraction/Quality Assessment. A data collection form was designed prior to the implementation of the search strategy. Two reviewers extracted independently the relevant information from the selected studies (Mashael K. Alshaikh and Juren P. Baldove). The data collection form included author name and published year, study location, population, repose rate, region, study type, sample size, and sampling method. The tools used are illustrated in Table 1.

We excluded all review articles, studies on children and adolescents, studies not undertaken in Saudi Arabia, and duplicates. The Newcastle-Ottawa Scale (NOS) was used to assess the quality of nonrandomised studies [80]. This NOS awards a maximum of nine stars to each study: four stars for the adequate selection of cohort studies, two stars for comparability of cohort studies on the basis of the design and analysis, and three stars for the assessing the outcome. We defined studies with NOS of $\geq 6$ stars as moderate- to high-quality studies and studies with a NOS of $<6$ stars as low-quality studies. Criteria for quality assessment and characteristics for each single study are shown in Table 2 (see Supplementary file* in Supplementary Material available online at http://dx.doi.org/10.1155/2016/7479357).

\section{Results}

Sixty-one studies were included in the systematic review that investigated the prevalence of CVD risk among women in Saudi Arabia (Figure 1: flow chart of study selection).
3.1. Cigarette Smoking. Seventeen studies reported on the prevalence of smoking among women. Ten studies were undertaken among university students $[20,23,25,26,29,30$, $32-35]$, two among employees [37, 38], one at a leisure place [40], one among people presenting in hospital [47], and three studies within national or regional populations [66, 67, 79]. The prevalence of smoking ranged from $1.1 \%$ to $9.1 \%$ in the above populations.

3.2. Hypertension $(B P \geq 140 / 90 \mathrm{mmHg}$ ). The prevalence of hypertension was reported in seventeen studies. Three were among university students [22, 25, 28], two were among employees [36, 37], two others were among healthy volunteers $[40,41]$, four were from primary care centers (PCCs) and health clinics [47, 51-53], and seven were conducted on a national or regional level [14, 57, 59, 62, 69, 70, 75]. Hypertension prevalence among university students was only $2.7 \%$, while the average prevalence among women was $21.8 \%$, the majority of whom were over age 40, from the PCCs and national studies (see Figure 2).

3.3. Diabetes. Twelve studies reported the prevalence of diabetes. Diabetes is an age-prevalent disease; as men or women get older, this increases the chance of having this disease detected. Two studies that were conducted among university students showed low prevalence, ranging from $1 \%$ to $2.1 \%[22,25]$, while among employees and healthy volunteers the diabetes prevalence ranged from $4 \%$ to $5.2 \%$ $[36,37,40]$. Seven studies reported on the prevalence among patients from the PCCs and at a national level that ranged from $9.6 \%$ to $27.6 \%$, most of them being over age 40 [14, 47, 48, 52, 54, 63, 78] (see Figure 3).

3.4. Overweight and Obesity. Thirteen studies reported the rate of being overweight in women. Five studies were carried out among university students [21, 22, 27, 28, 31], one was among employees [36], three were in PCCs [46, 48, 50], and 


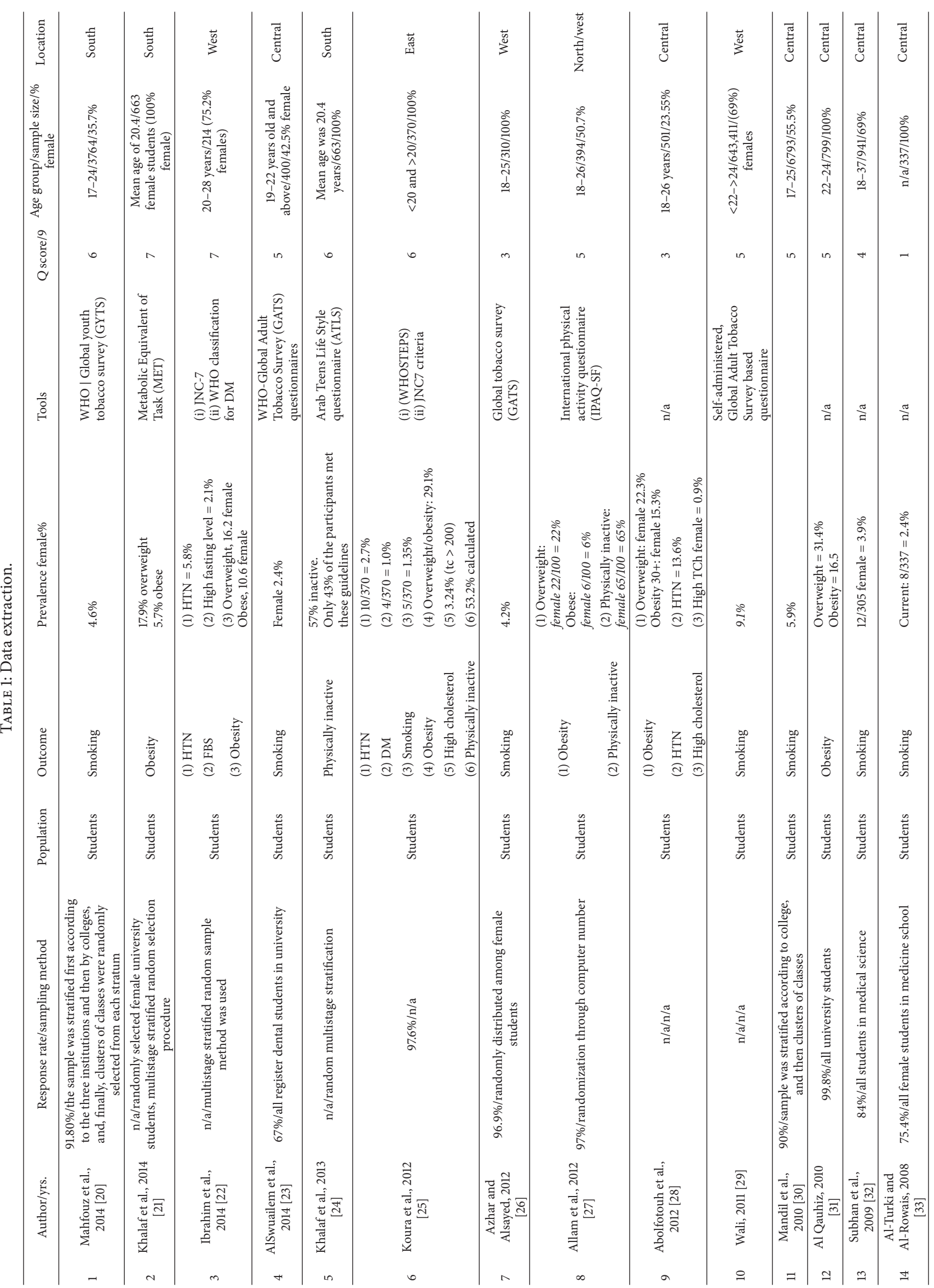




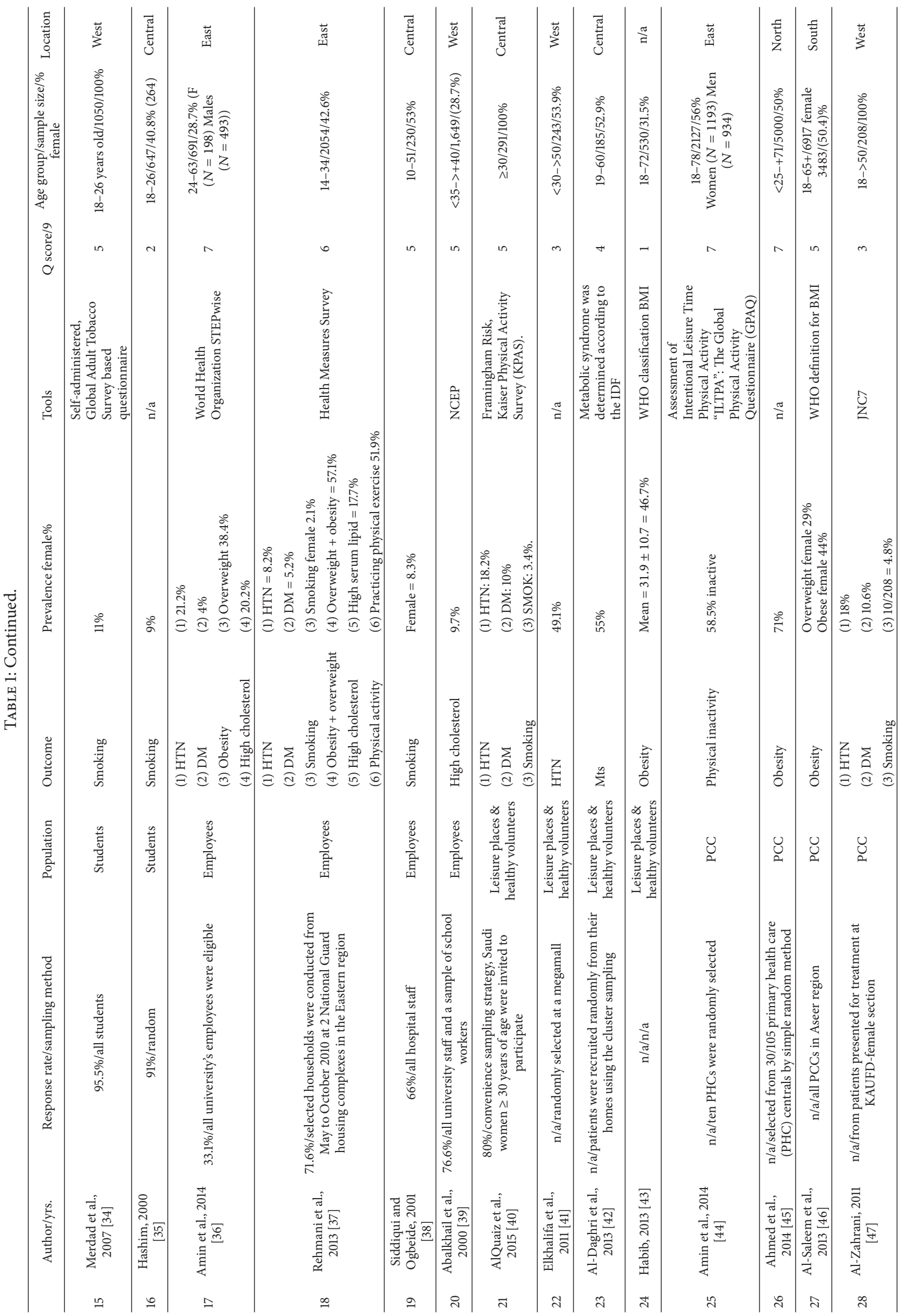




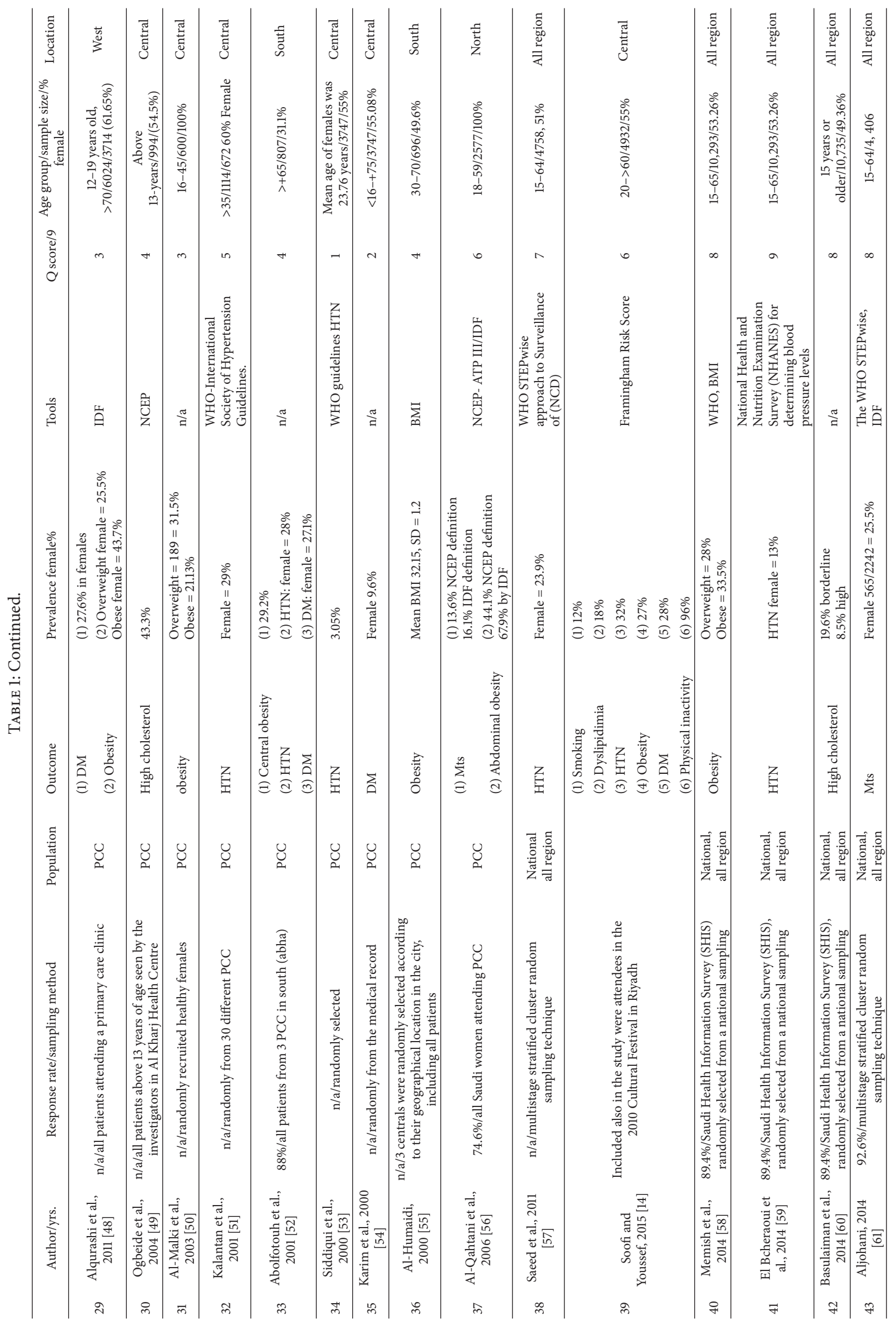




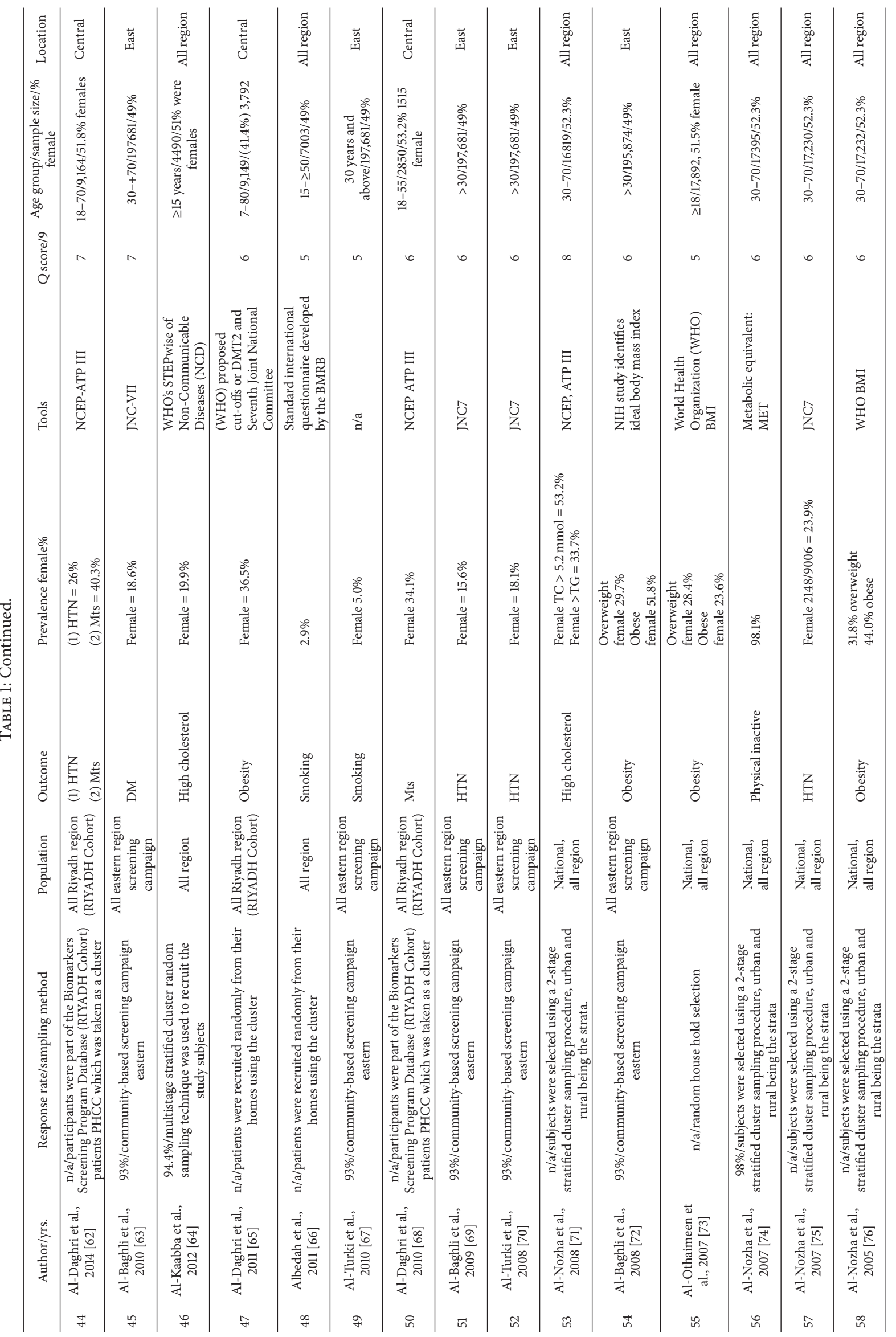




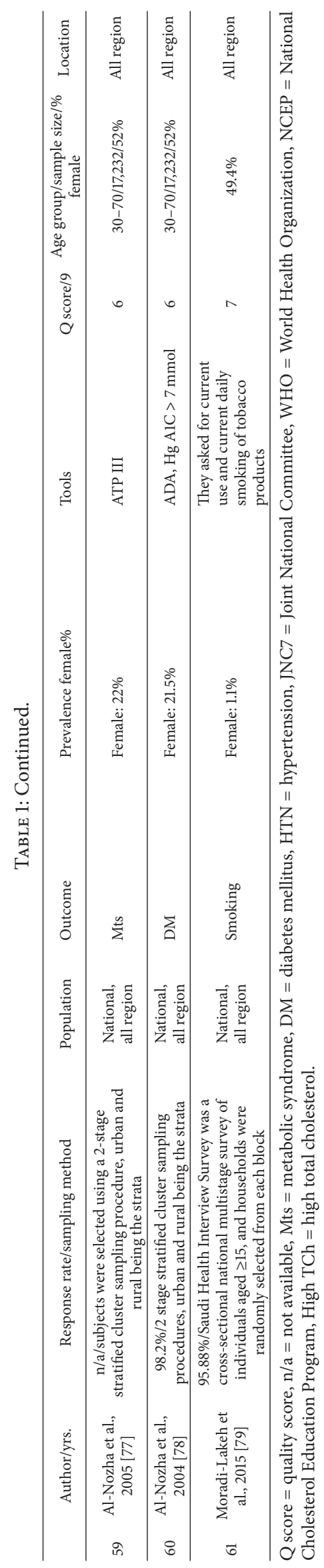




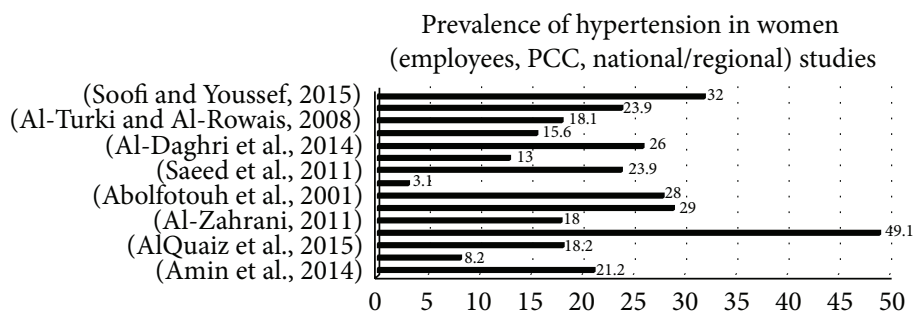

FIGURe 2: Prevalence of hypertension in women (employees, primary care centres, and national studies).

Diabetes among PCC and national/regional studies

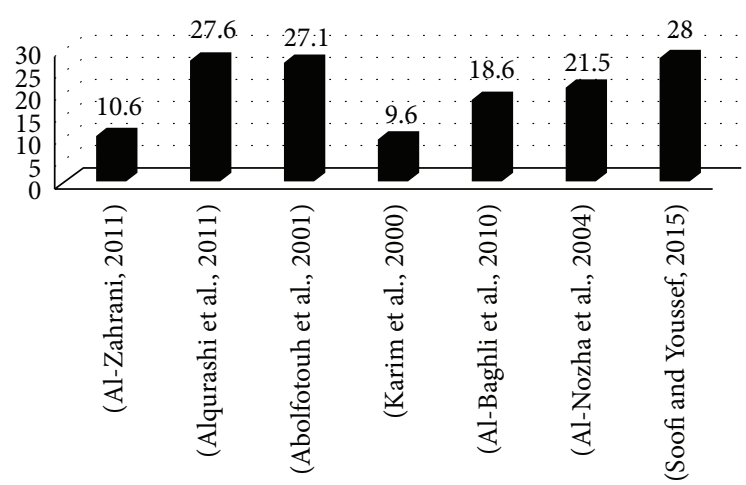

Figure 3: Prevalence of hypertension in women (employees, primary care centres, and national studies).

four were done on a national or regional level $[58,72,73,76]$. The average prevalence of overweight among women was $27 \%$, and it ranged from $16.2 \%$ to $38.4 \%$ (see Figure 4 ).

Twenty studies reported the prevalence of obesity, six among university students [21, 22, 25, 27, 28, 31], and the prevalence of obesity ranged from $5.7 \%$ to $29 \%$ with this population. Two studies were conducted with employees and healthy volunteers, where the prevalence of obesity was $57.1 \%$ and $46.7 \%$, respectively. Seven studies were conducted in PCCs $[45,46,48,50,52,55,56]$ and six on a national or regional level $[14,58,65,72,73,76]$. The average prevalence within PCCs and national studies was $40.23 \%$, and it ranged between 21.13 and $71 \%$ (see Figure 5).

3.5. Hypercholesterolemia. Nine studies reported the prevalence of hypercholesterolemia; two were among students $[25,28]$, three were among employees $[36,37,39]$, and one was in PCCs [49]. Three further studies were carried out on a national level $[60,64,71]$. There were various cutoff points in defining hypercholesterolemia used among the studies, which reduces their comparability. For example, in the two national data studies, $[64,71]$ hypercholesterolemia was defined as levels of cholesterol $>5.2 \mathrm{mmol} / \mathrm{L}$, while Basulaiman et al. [60] used a measure of $>6.2 \mathrm{mmol} / \mathrm{L}$. The average of hypercholesterolemia prevalence in all the studies was found to be $24 \%$.

3.6. Physical Inactivity. The prevalence of physical inactivity was reported in seven studies [14, 24, 25, 27, 37, 44, 74]. The
Overweight

(PCC and national studies)

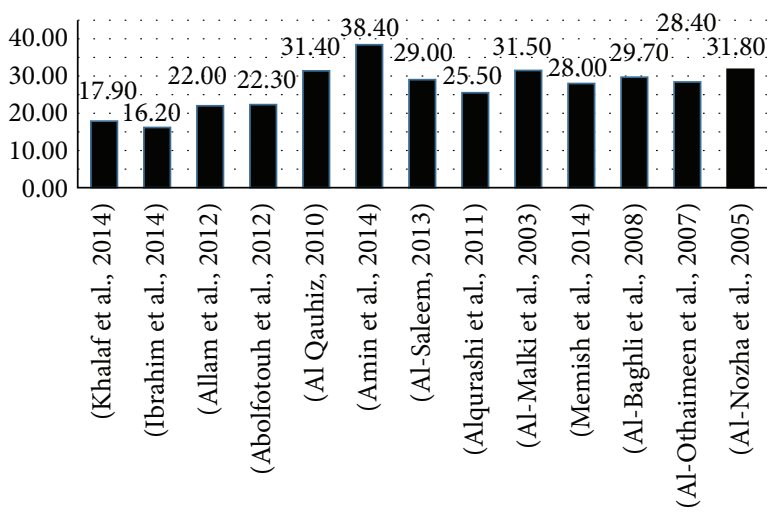

FIgURE 4: Prevalence of overweight in women (primary care centres and national studies).

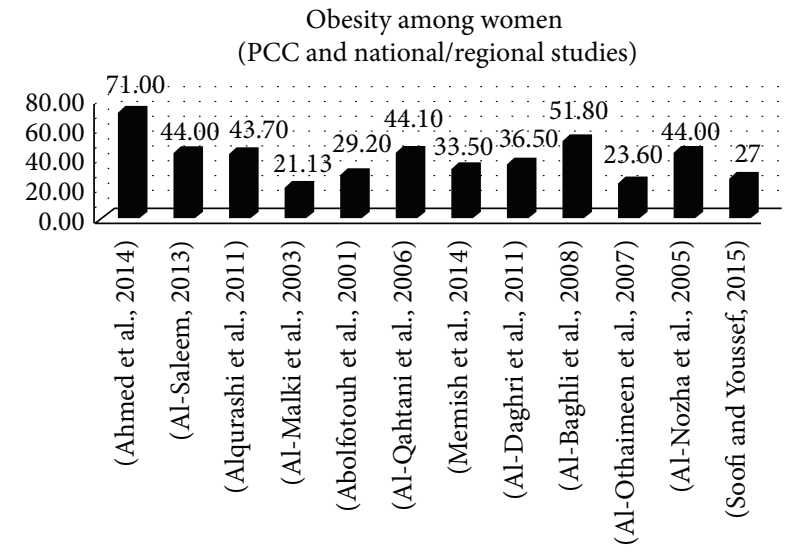

FIGURE 5: Prevalence of obesity in women (primary care centres and national studies).

rates ranged from $53.2 \%$ to $98.1 \%$, and one study was done on a national level [74].

3.7. Metabolic Syndrome. Six studies reported on the prevalence of metabolic syndrome, four of which used the National Cholesterol Education Program Adult Treatment Panel (NCEP ATP) III definition [56, 62, 68, 77]. Metabolic syndrome rates ranged from $13.6 \%$ to $40.3 \%$, reporting on a national level and from patients attending PCCs. Two studies 
used the International Diabetes Federation (IDF) definition $[42,61]$ in which the rates ranged between $25.5 \%$ and $55 \%$.

\section{Discussion}

Our review of the studies identifies a consistently high prevalence of obesity, diabetes, hypertension, and physical inactivity among women in Saudi Arabia, especially obesity and physical inactivity. These conditions can be affected or prevented by changes in behaviours and lifestyles. We noted that almost half of the women population are obese and three quarter are not physically active. The majority of studies have been done in the central region which may be due to the higher population density in that area, followed by the eastern and western regions, while the least has been done in the northern region. The overall quality of the included studies varied, half of the studies were high- to moderate-quality score (6-9), and the rest were lower score (5-1), whereas five studies score $\leq 2$.

4.1. Obesity. Obesity predisposes a person to a number of cardiovascular risk factors, including diabetes, hypertension, and dyslipidaemia. The overall prevalence of obesity in adult females in Saudi Arabia is one of the highest amongst females, worldwide [12]. The study used data from the Saudi national health survey showed that $28.7 \%$ of the population aged 15 years old and above were obese with prevalence of $24.1 \%$ among men and $33.5 \%$ among women. The risk of obesity in Saudi women, the study showed, increases with a number of risk factors including age, being married or previously married, being diagnosed with a chronic condition, and being prehypertensive or hypertensive. Moreover, women who were more educated are less likely to be obese than those who had a primary school educational level or less [58]. We found that the prevalence of being overweight varied between $16 \%$ and $36.4 \%$, and for obesity $21.3 \%$ and $71 \%$. This was more than the obesity levels reported in Lebanon and Tunisia, but less than in Kuwait and Egypt [81]. Moreover, the prevalence of overweight (26\%) and obesity (29\%) in Saudi women aged 20 to 39 years was higher than that in the USA [82].

4.2. Diabetes. Diabetes is well known to be a coronary artery disease risk equivalent, and also, many studies have demonstrated a worse outcome for diabetic patients with ACS compared with nondiabetic patients [83, 84]. According to the SPACE registry, more than half of the patients with ACS have diabetes [16]. Diabetes prevalence among the GCC countries is considered to be one of the highest in the world [85]. Besides, the prevalence of diabetes among Saudi Arabia's population increased by $15 \%$ over the period from 1987 to 2011 [86]. Data from the Saudi Health Interview Survey (SHIS) found that the prevalence of diabetes among Saudi women was at $11.7 \%$. Although the recent findings showed that the prevalence of diabetes in Saudi women is decreasing, the demographic characteristics however like age and marital status were strongly associated with being borderline diabetic or diabetic. They are also more prone to be diabetic if they are older, separated, divorced, or widowed. The findings also showed that Saudi diabetic women do not receive a routine medical examination, self-rated as health-poor health, and a significant percentage of diabetic women at $48.4 \%$ were undiagnosed, and $27.8 \%$ of those receiving treatment had uncontrolled diabetes [87]. In this review, the average prevalence of diabetes among women was 20.4\%. Saudi Arabia has one of the world's highest incident rates of diabetes; according to the International Diabetic Federation (IDF) there were 3.4 million diabetes cases within Saudi Arabia in 2015, and the prevalence of diabetes among adults aged $20-79$ is $17.6 \%$ [88]. Furthermore, the incident rate of diabetes increases with the degree and duration of being overweight or obese as high prevalence of obesity and physical inactivity contribute to the development of insulin resistance and metabolic syndrome [89].

4.3. Hypertension. Aetiologically, coronary artery disease is closely tied to diabetes and hypertension. As mentioned previously according to SPACE registry more than 55\% of the patients with ACS have hypertension [16]. In this review, the average prevalence of hypertension was $21.8 \%$. The last SHIS report showed that prevalence of hypertension was $12.5 \%$ among Saudi women. Although the risk of being hypertensive was lower among females compared to men, however, it increases with age, being obese, diabetes, and hypercholesterolemia. Age and last routine medical exam were significantly associated with women having undiagnosed hypertension or having borderline hypertension or being hypertensive. The risk of being hypertensive was higher among women who were separated, divorced, or widowed. However, educated women with college degrees or higher are less likely to be hypertensive. Similarly, the findings on the prevalence of hypertension may be subsiding; still more than half of the hypertensive Saudis are undiagnosed at $57.8 \%$ and $55.0 \%$ of those on treatment were not controlled, respectively [59, 87]. Tailakh et al. reported the prevalence of hypertension among ten Arab countries including Saudi Arabia in their systematic review. The overall estimated prevalence was $29.5 \%$. In five out of the thirteen studies women were more hypertensive than men. While two studies showed that men have a higher prevalence of hypertension, the rest of the studies reported no difference between genders [90]. Comparing to the USA, according to the US National Health and Nutrition Examination Survey, the prevalence of hypertension was $27.1 \%$ in men and $30.1 \%$ in women [91]. Although the prevalence of the hypertension amongst Arabs and Saudis is lower than in the US data, the number may be much more than what is reported according to Tailakh et al. review, and from the SHIS report, because the majority of the hypertensive patients were unaware of their hypertension, due to issues such as illiteracy $[59,90]$.

4.4. Physical Inactivity. Physical inactivity is globally more prevalent among women than among their male counterpart [92]. Similarly, physical inactivity and a sedentary lifestyle have been reported as high within Muslim countries, with an overall prevalence of $32.3 \%$, and even higher in women $35.5 \%$ [93]. In addition, in GCC countries, Aljefree and Ahmed 
reported a low level of activity among women. In Saudi Arabia, women's activities are limited because of cultural and religious norms, and women are prohibited from driving and require a guardian for transportation to go to a place such as a health club. This increases the personal burden of attending and limits their physical activities. Further, there is no physical activity in the school curriculum for girls in Saudi public schools [17]. In our study, we found a high rate of reported physical inactivity, ranging between $53.2 \%$ and $98.1 \%$ more than the reported numbers for the opposite gender in the Saudi community [74].

4.5. Hypercholesterolemia. The prevalence of hypercholesterolemia among women in the GCC region ranged from $9 \%$ to $53.2 \%$ [12]. This review found that different studies used different measures of hypercholesterolemia. For example, Basulaiman et al. [60] defined hypercholesterolemia with $6.2 \mathrm{mmol} / \mathrm{L}$ as a cut-off point, while in Al-Nozha et al. [71] a measure of $5.2 \mathrm{mmol} / \mathrm{L}$ was used to define hypercholesterolemia. This could explain the higher prevalence in the Al-Nozha study [60, 71]. In addition, hypercholesterolemia is significantly associated along with age, type of fat consumed, obesity, and diagnosis history of hypertension and diabetes among Saudis [60]. Also, the prevalence of hypercholesterolemia among Saudi women was at 7.3\% while women who watch five hours of television or more daily were twice as likely to be borderline hypercholesterolemic [87].

4.6. Smoking. The rate of cigarette smoking in women in the GCC region ranges from $0.5 \%$ to $20.7 \%$ [12]. This review revealed rates ranging from $2.5 \%$ to $9.1 \%$ in women, while among men the prevalence of smoking ranged from 11.6 to $52.3 \%$ [94]. The SHIS survey reported that approximately $1.4 \%$ of the population were daily smokers of both cigarette/cigar and shisha at $2.6 \%$ in men and $0.1 \%$ in women. Saudis aged 15 to 64 years who were smoking shisha increased from $3.34 \%$ to $7.35 \%$ in men and from 0.5 to $1.28 \%$ in women. The study also revealed that $23.3 \%$ of the Saudi population with $32.3 \%$ of men and $13.5 \%$ of women were exposed to second-hand smoke for at least one day during the prior 7 days at home, work, or school [79]. Although there are many reported surveys on the increasing number of female smokers, especially those smoking the hookah (water pipe), this review only covers the smoking of cigarettes. A systematic review carried out in 2011 reported that the prevalence of water pipe smoking in Saudi Arabia ranged from $9 \%$ to $10 \%$ [95]. The problem may even be greater, as many national surveys do not mention second-hand smoke among women or families as part of CVD risks nor is it culturally acceptable for women to smoke. The actual number of women smoking within Saudi Arabia could therefore be significantly underestimated.

4.7. Metabolic Syndrome. The metabolic syndrome is a cluster of risk factors (including obesity, dyslipidaemia, hypertension, and impaired glucose metabolism) that have been shown to be strongly predictive of cardiovascular disease [96]. Mabry et al. reported the prevalence of metabolic syndrome among men and women within the GCC countries ranged from $20.7 \%$ to $37.2 \%$ (ATPIII definition) and from $29.6 \%$ to $36.2 \%$ (IDF definition) for men and for women, from $32.1 \%$ to $42.7 \%$ (ATPIII definition) and from $36.1 \%$ to $45.9 \%$ (IDF definition) [97]. In this review, Saudi women had a prevalence close to women in other GCC countries with rates varying between $13.6 \%$ and $40.3 \%$ (ATPIII definition) and 25.5 and $55 \%$ (IDF definition).

4.8. Challenges Facing Saudi Women in Adapting Healthy Lifestyle. The majority of the reported studies from the national data shows that Saudis have high rates of diagnosed and undiagnosed chronic diseases, and both genders have similar concerns in terms of health seeking behaviour; about $22.4 \%$ only of Saudi women received a periodic health examination within the last 2 years as compared to $23.3 \%$ of men [98]. However, women in Saudi Arabia may have difficulty in engaging in a lifestyle as healthy (e.g., gym use) as they would like to be due to mobility restrictions. This is an important obstacle to deal with, as women in Saudi cannot drive and need the presence of a male relative to go to and avail the services of a healthcare facility. Though, over the past 10 years Saudi women have had growing participation in senior management positions and in the decision-making process in public and private sectors which may, over time, lead to improved health status for all women. Empowerment of women was the main focus of the Saudi government, under King Abdullah [99]. This emphasis could influence women's health and possibly give more power to women and change the social norm by forcing a focus on women's health needs and to facilitate the adaptation of healthier lifestyles.

\section{Limitation}

There was significant heterogeneity between studies with respect to definitions of risk factors, design, and population characteristics. In addition, the lack of standardization for the definition of dyslipidaemia limits our ability to provide summary estimates for this important risk factor. Likewise, the majority of the tools used for measuring physical inactivity varied between studies.

\section{Conclusion}

This is the first systematic review to focus exclusively on the women's dimension of CVD risk factors and the unique social and cultural context in which CVD risk is evaluated and managed in Saudi women. There were several methodological challenges, in particular, the different populations studied and the methods used to assess the prevalence of CVD risks. In summary, the prevalence of CVD risk factors is high among women in Saudi Arabia, particularly obesity and physical inactivity. We need health promotion programs and reorientation of primary health care to improve CVD detection at earlier stages and improve its management. Public health authorities need to consider gender specific aspects of the problem in order to decrease the rising trend of CVD prevalence in Saudi Arabia implementing programs to 
influence change in social norms in order to create a healthier and more active society.

\section{Competing Interests}

No conflict of interests was declared.

\section{Acknowledgments}

This research was supported by sponsorship provided to Mashael Alshaikh, by King Saud University, Riyadh, Saudi Arabia. The Department of Primary Care and Public Health at Imperial College London is grateful for support from the National Institute for Health Research (NIHR) Collaboration for Leadership in Applied Health Research \& Care (CLAHRC) scheme, the NIHR Biomedical Research Centre scheme, and the Imperial Centre for Patient Safety and Service Quality.

\section{References}

[1] World Health Organization (WHO), Global Atlas on cardiovascular disease prevention and control 2011, http://whqlibdoc. who.int/publications/2011/9789241564373_eng.pdf.

[2] S. C. Smith Jr., A. Collins, R. Ferrari et al., "Our time: a call to save preventable death from cardiovascular disease (heart disease and stroke)," Journal of the American College of Cardiology, vol. 60, no. 22, pp. 2343-2348, 2012.

[3] R. B. D’Agostino Sr., R. S. Vasan, M. J. Pencina et al., "General cardiovascular risk profile for use in primary care: the Framingham heart study," Circulation, vol. 117, no. 6, pp. 743-753, 2008.

[4] T. A. Gaziano, "Reducing the growing burden of cardiovascular disease in the developing world," Health Affairs, vol. 26, no. 1, pp. 13-24, 2007.

[5] S. Mendis, "The contribution of the Framingham Heart Study to the prevention of cardiovascular disease: a global perspective," Progress in Cardiovascular Diseases, vol. 53, no. 1, pp. 10-14, 2010.

[6] World Health Organization (WHO), Prevention of Cardiovascular Disease Guidelines for assessment and management of cardiovascular risk 2007, http://www.who.int/cardiovascular_diseases/guidelines/Full\%20text.pdf.

[7] T. Karwalajtys and J. Kaczorowski, "An integrated approach to preventing cardiovascular disease: community-based approaches, health system initiatives, and public health policy," Risk Management and Healthcare Policy, vol. 3, pp. 39-48, 2010.

[8] S. Yusuf, S. Reddy, S. Ounpuu, and S. Anand, "Global burden of cardiovascular diseases: part I: general considerations, the epidemiologic transition, risk factors, and impact of urbanization," Circulation, vol. 104, no. 22, pp. 2746-2753, 2001.

[9] W. Almahmeed, M. S. Arnaout, R. Chettaoui et al., "Coronary artery disease in Africa and the Middle East," Therapeutics and Clinical Risk Management, vol. 8, pp. 65-72, 2012.

[10] F. A. Akala and S. El-Saharty, "Public-health challenges in the Middle East and North Africa," The Lancet, vol. 367, no. 9515, pp. 961-964, 2006.

[11] H. F. Abdul Rahim, A. Sibai, Y. Khader et al., "Non-communicable diseases in the Arab world," The Lancet, vol. 383, no. 9914, pp. 356-367, 2014.

[12] N. Aljefree and F. Ahmed, "Prevalence of cardiovascular disease and associated risk factors among adult population in the Gulf region: a systematic review," Advances in Public Health, vol. 2015, Article ID 235101, 23 pages, 2015.

[13] MOH, Health Statistical Year Book, MOH, 2011.

[14] M. A. Soofi and M. A. Youssef, "Prediction of 10-year risk of hard coronary events among Saudi adults based on prevalence of heart disease risk factors," Journal of the Saudi Heart Association, vol. 27, no. 3, pp. 152-159, 2015.

[15] B. Bdeir, I. Farah, and T. Conboy, "Managing cardiovascular disease: model of care in Saudi Arabia," European Heart Journal Supplements, vol. 16, supplement, pp. B96-B98, 2014.

[16] K. F. AlHabib, A. Hersi, H. AlFaleh et al., "Baseline characteristics, management practices, and in-hospital outcomes of patients with acute coronary syndromes: results of the Saudi project for assessment of coronary events (SPACE) registry," Journal of the Saudi Heart Association, vol. 23, no. 4, pp. 233239, 2011.

[17] E. S. Al-Eisa and H. I. Al-Sobayel, "Physical activity and health beliefs among Saudi women," Journal of Nutrition and Metabolism, vol. 2012, Article ID 642187, 6 pages, 2012.

[18] A. E. H. Mobaraki and B. Söderfeldt, "Gender inequity in Saudi Arabia and its role in public health," Eastern Mediterranean Health Journal, vol. 16, no. 1, pp. 113-118, 2010.

[19] M. A. El-Hazmi and A. S. Warsy, "Prevalence of overweight and obesity in diabetic and non-diabetic Saudis," Eastern Mediterranean Health Journal, vol. 6, no. 2-3, pp. 276-282, 2000.

[20] M. S. Mahfouz, R. M. Alsanosy, A. M. Gaffar, and A. Makeen, "Tobacco use among university students of Jazan Region: gender differences and associated factors," BioMed Research International, vol. 2014, Article ID 279231, 7 pages, 2014.

[21] A. Khalaf, A. Westergren, V. Berggren, Ö. Ekblom, and H. M. Al-Hazzaa, "Prevalence and association of female weight status and dietary habits with sociodemographic factors: a crosssectional study in Saudi Arabia," Public Health Nutrition, vol. 18, no. 5, pp. 784-796, 2014.

[22] N. K. Ibrahim, M. Mahnashi, A. Al-Dhaheri et al., "Risk factors of coronary heart disease among medical students in King Abdulaziz University, Jeddah, Saudi Arabia," BMC Public Health, vol. 14, article 411, 2014.

[23] A. S. AlSwuailem, M. K. AlShehri, and S. Al-Sadhan, "Smoking among dental students at King Saud University: consumption patterns and risk factors," The Saudi Dental Journal, vol. 26, no. 3, pp. 88-95, 2014.

[24] A. Khalaf, Ö. Ekblom, J. Kowalski, V. Berggren, A. Westergren, and H. Al-Hazzaa, "Female university students' physical activity levels and associated factors-a cross-sectional study in southwestern Saudi Arabia," International Journal of Environmental Research and Public Health, vol. 10, no. 8, pp. 3502-3517, 2013.

[25] M. R. Koura, B. K. Al-Dabal, P. Rasheed, L. S. Al-Sowielem, and S. M. Makki, "Prehypertension among young adult females in Dammam, Saudi Arabia," Eastern Mediterranean Health Journal, vol. 18, no. 7, pp. 728-734, 2012.

[26] A. Azhar and N. Alsayed, "Prevalence of smoking among female medical students in Saudai Arabia," Asian Pacific Journal of Cancer Prevention, vol. 13, no. 9, pp. 4245-4248, 2012.

[27] A. R. Allam, I. M. Taha, O. M. Al-Nozha, and I. E. Sultan, "Nutritional and health status of medical students at a university in Northwestern Saudi Arabia," Saudi Medical Journal, vol. 33, no. 12, pp. 1296-1303, 2012.

[28] M. A. Abolfotouh, I. A. Al-Alwan, and M. A. Al-Rowaily, "Prevalence of metabolic abnormalities and association with obesity among Saudi college students," International Journal of Hypertension, vol. 2012, Article ID 819726, 8 pages, 2012. 
[29] S. O. Wali, "Smoking habits among medical students in Western Saudi Arabia," Saudi Medical Journal, vol. 32, no. 8, pp. 843-848, 2011.

[30] A. Mandil, A. BinSaeed, S. Ahmad, R. Al-Dabbagh, M. Alsaadi, and M. Khan, "Smoking among university students: a gender analysis," Journal of Infection and Public Health, vol. 3, no. 4, pp. 179-187, 2010.

[31] N. M. Al Qauhiz, "Obesity among Saudi Female University Students: dietary habits and health behaviors," The Journal of the Egyptian Public Health Association, vol. 85, no. 1-2, pp. 45-59, 2010.

[32] M. M. Subhan, T. Al-Khlaiwi, and S. O. Ghandourah, "Smoking among health science university students in Riyadh, Saudi Arabia," Saudi Medical Journal, vol. 30, no. 12, pp. 1610-1612, 2009.

[33] Y. A. Al-Turki and N. A. Al-Rowais, "Prevalence of smoking among female medical students in the College of Medicine, Riyadh, Saudi Arabia," Saudi Medical Journal, vol. 29, no. 2, pp. 311-312, 2008.

[34] L. A. Merdad, M. S. Al-Zahrani, and J. M. A. Farsi, "Smoking habits among Saudi female university students: prevalence, influencing factors and risk awareness," Annals of Saudi Medicine, vol. 27, no. 5, pp. 366-369, 2007.

[35] T. J. Hashim, "Smoking habits of students in College of Applied Medical Science, Saudi Arabia," Saudi Medical Journal, vol. 21, no. 1, pp. 76-80, 2000.

[36] T. T. Amin, A. I. Al Sultan, O. A. Mostafa, A. A. Darwish, and M. R. Al-Naboli, "Profile of non-communicable disease risk factors among employees at a Saudi University," Asian Pacific Journal of Cancer Prevention, vol. 15, no. 18, pp. 7897-7907, 2014.

[37] R. Rehmani, A. G. Elzubair, M. Al Maani et al., "Populationbased health survey in eastern region of Saudi Arabia," Eastern Mediterranean Health Journal, vol. 19, no. 5, pp. 417-425, 2013.

[38] S. Siddiqui and D. O. Ogbeide, "Profile of smoking amongst health staff in a primary care unit at general hospital in Riyadh, Saudi Arabia," Saudi Medical Journal, vol. 22, no. 12, pp. 11011104, 2001.

[39] B. A. Abalkhail, S. Shawky, T. M. Ghabrah, and W. A. Milaat, "Hypercholesterolemia and 5-year risk of development of coronary heart disease among university and school workers in Jeddah, Saudi Arabia," Preventive Medicine, vol. 31, no. 4, pp. 390-395, 2000.

[40] A. M. AlQuaiz, A. Kazi, R. Qureshi, A. R. Siddiqui, A. Jamal, and S. A. Shaik, "Correlates of cardiovascular disease risk scores in women in Riyadh, Kingdom of Saudi Arabia," Women \& Health, vol. 55, no. 1, pp. 103-117, 2015.

[41] A. M. Elkhalifa, A. J. Kinsara, and D. A. Almadani, "Prevalence of hypertension in a population of healthy individuals," Medical Principles \& Practice, vol. 20, no. 2, pp. 152-155, 2011.

[42] N. M. Al-Daghri, N. Khan, K. M. Alkharfy et al., "Selected dietary nutrients and the prevalence of metabolic syndrome in adult males and females in Saudi Arabia: a pilot study," Nutrients, vol. 5, no. 11, pp. 4587-4604, 2013.

[43] S. S. Habib, "Body mass index and body fat percentage in assessment of obesity prevalence in Saudi adults," Biomedical and Environmental Sciences, vol. 26, no. 2, pp. 94-99, 2013.

[44] T. T. Amin, A. M. Al-Hammam, N. A. AlMulhim et al., "Physical activity and cancer prevention: awareness and meeting the recommendations among adult Saudis," Asian Pacific Journal of Cancer Prevention, vol. 15, no. 6, pp. 2597-2606, 2014.
[45] H. G. Ahmed, I. A. Ginawi, A. M. Elasbali, I. M. Ashankyty, and A. M. Al-Hazimi, "Prevalence of obesity in hail region, KSA: in a comprehensive survey," Journal of Obesity, vol. 2014, Article ID 961861, 5 pages, 2014.

[46] S. A. Al-Saleem, A. M. Alshahrani, and Y. M. Al-Khaldi, "Obesity among patients attending primary care centers, Aseer Region, Saudi Arabia," Saudi Journal of Obesity, vol. 1, no. 2, pp. 67-70, 2013.

[47] M. S. Al-Zahrani, "Prehypertension and undiagnosed hypertension in a sample of dental school female patients," International Journal of Dental Hygiene, vol. 9, no. 1, pp. 74-78, 2011.

[48] K. A. Alqurashi, K. S. Aljabri, and S. A. Bokhari, "Prevalence of diabetes mellitus in a Saudi community," Annals of Saudi Medicine, vol. 31, no. 1, pp. 19-23, 2011.

[49] D. O. Ogbeide, A. Karim, I. M. Al-Khalifa, and S. Siddique, "Population based study of serum lipid levels in Al-Kharj Health Center, Saudi Arabia," Saudi Medical Journal, vol. 25, no. 12, pp. 1855-1857, 2004.

[50] J. S. Al-Malki, M. H. Al-Jaser, and A. S. Warsy, "Overweight and obesity in Saudi females of childbearing age," International Journal of Obesity and Related Metabolic Disorders: Journal of the International Association for the Study of Obesity, vol. 27, no. 1, pp. 134-139, 2003.

[51] K. A. Kalantan, A. G. Mohamed, A. A. Al-Taweel, and H. M. Abdul Ghani, "Hypertension among attendants of primary health care centers in Al-Qassim region, Saudi Arabia," Saudi Medical Journal, vol. 22, no. 11, pp. 960-963, 2001.

[52] M. A. Abolfotouh, A. A. Daffallah, M. Y. Khan, M. S. Khattab, and I. Abdulmoneim, "Central obesity in elderly individuals in south-western Saudi Arabia: prevalence and associated morbidity," Eastern Mediterranean Health Journal, vol. 7, no. 4-5, pp. 716-724, 2001.

[53] S. Siddiqui, D. O. Ogbeide, A. Karim, and I. Al-Khalifa, "Prevalence of hypertension in a mixed community," Saudi Medical Journal, vol. 21, no. 6, pp. 558-560, 2000.

[54] A. Karim, D. O. Ogbeide, S. Siddiqui, and I. M. Al-Khalifa, "Prevalence of diabetes mellitus in a Saudi community," Saudi Medical Journal, vol. 21, no. 5, pp. 438-442, 2000.

[55] M. A. Al-Humaidi, "Probability of coronary artery disease among patients attending primary health care centers (PHCCs) in Southwest Saudi Arabia," Ethnicity \& Disease, vol. 10, no. 3, pp. 350-356, 2000.

[56] D. A. Al-Qahtani, M. L. Imtiaz, O. S. Saad, and N. M. Hussein, "A comparison of the prevalence of metabolic syndrome in Saudi adult females using two definitions," Metabolic Syndrome and Related Disorders, vol. 4, no. 3, pp. 204-214, 2006.

[57] A. A. Saeed, N. A. Al-Hamdan, A. A. Bahnassy, A. M. Abdalla, M. A. F. Abbas, and L. Z. Abuzaid, "Prevalence, awareness, treatment, and control of hypertension among Saudi adult population: a national survey," International Journal of Hypertension, vol. 2011, Article ID 174135, 8 pages, 2011.

[58] Z. A. Memish, C. El Bcheraoui, M. Tuffaha et al., "Obesity and associated factors-Kingdom of Saudi Arabia, 2013," Preventing Chronic Disease, vol. 11, Article ID 140236, 2014.

[59] C. El Bcheraoui, Z. A. Memish, M. Tuffaha et al., "Hypertension and its associated risk factors in the Kingdom of Saudi Arabia, 2013: a national survey," International Journal of Hypertension, vol. 2014, Article ID 564679, 8 pages, 2014.

[60] M. Basulaiman, C. El Bcheraoui, M. Tuffaha et al., "Hypercholesterolemia and its associated risk factors-Kingdom of Saudi Arabia, 2013," Annals of Epidemiology, vol. 24, no. 11, pp. 801808, 2014. 
[61] N. J. Aljohani, "Metabolic syndrome: risk factors among adults in Kingdom of Saudi Arabia," Journal of Family \& Community Medicine, vol. 21, no. 3, pp. 170-175, 2014.

[62] N. M. Al-Daghri, K. M. Alkharfy, O. S. Al-Attas et al., "Genderdependent associations between socioeconomic status and metabolic syndrome: a cross-sectional study in the adult Saudi population," BMC Cardiovascular Disorders, vol. 14, article 51, 2014.

[63] N. A. Al-Baghli, A. J. Al-Ghamdi, K. A. Al-Turki, A. H. Al Elq, A. G. El-Zubaier, and A. Bahnassy, "Prevalence of diabetes mellitus and impaired fasting glucose levels in the Eastern Province of Saudi Arabia: results of a screening campaign," Singapore Medical Journal, vol. 51, no. 12, pp. 923-930, 2010.

[64] A. F. Al-Kaabba, N. A. Al-Hamdan, A. El Tahir, A. M. Abdalla, A. A. Saeed, and M. A. Hamza, "Prevalence and correlates of dyslipidemia among adults in Saudi Arabia: results from a national survey," Journal of Endocrine and Metabolic Diseases, vol. 2, no. 4, pp. 89-97, 2012.

[65] N. M. Al-Daghri, O. S. Al-Attas, M. S. Alokail et al., "Diabetes mellitus type 2 and other chronic non-communicable diseases in the central region, Saudi Arabia (Riyadh cohort 2): a decade of an epidemic," BMC Medicine, vol. 9, article 76, 2011.

[66] A. M. Albedah, M. K. Khalil, A. A. Khalil, and A. T. Elolemy, "Use of the target group index survey to evaluate the cigarette smoking profile in Saudi Arabia," Saudi Medical Journal, vol. 32, no. 10, pp. 1055-1059, 2011.

[67] K. A. Al-Turki, N. A. Al-Baghli, A. J. Al-Ghamdi, A. G. ElZubaier, R. Al-Ghamdi, and M. M. Alameer, "Prevalence of current smoking in eastern province, Saudi Arabia," Eastern Mediterranean Health Journal, vol. 16, no. 6, pp. 671-676, 2010.

[68] N. M. Al-Daghri, O. S. Al-Attas, M. S. Alokail, K. M. Alkharfy, S. L. B. Sabico, and G. P. Chrousos, "Decreasing prevalence of the full metabolic syndrome but a persistently high prevalence of dyslipidemia among adult Arabs," PLoS ONE, vol. 5, no. 8, Article ID e12159, 2010.

[69] N. A. Al-Baghli, K. A. Al-Turki, A. J. Al-Ghamdi, A. G. ElZubaier, F. A. Al-Baghli, and N. H. Bohlaiqa, "Control of hypertension in eastern Saudi Arabia: results of screening campaign," Journal of Family and Community Medicine, vol. 16, no. 1, pp. 19-25, 2009.

[70] K. A. Al-Turki, N. A. Al-Baghli, A. J. Al-Ghamdi, and A. G. El-Zubaier, "Hypertension in the Eastern province of Saudi Arabia: results of a screening campaign," Journal of Family and Community Medicine, vol. 15, no. 3, pp. 95-101, 2008.

[71] M. M. Al-Nozha, M. R. Arafah, M. A. Al-Maatouq et al., "Hyperlipidemia in Saudi Arabia," Saudi Medical Journal, vol. 29, no. 2, pp. 282-287, 2008.

[72] N. A. Al-Baghli, A. J. Al-Ghamdi, K. A. Al-Turki, A. G. ElZubaier, M. Al-Ameer, and F. A. Al-Baghli, "Overweight and obesity in the eastern province of Saudi Arabia," Saudi Medical Journal, vol. 29, no. 9, pp. 1319-1325, 2008.

[73] A. I. Al-Othaimeen, M. Al-Nozha, and A. K. Osman, "Obesity: an emerging problem in Saudi Arabia. Analysis of data from the national nutrition survey," Eastern Mediterranean Health Journal, vol. 13, no. 2, pp. 441-448, 2007.

[74] M. M. Al-Nozha, H. M. Al-Hazzaa, M. R. Arafah et al., "Prevalence of physical activity and inactivity among Saudis aged 30-70 years. A population-based cross-sectional study," Saudi Medical Journal, vol. 28, no. 4, pp. 559-568, 2007.

[75] M. M. Al-Nozha, M. Abdullah, M. R. Arafah et al., "Hypertension in Saudi Arabia," Saudi Medical Journal, vol. 28, no. 1, pp. 77-84, 2007.
[76] M. M. Al-Nozha, Y. Y. Al-Mazrou, M. A. Al-Maatouq et al., "Obesity in Saudi Arabia," Saudi Medical Journal, vol. 26, no. 5, pp. 824-829, 2005.

[77] M. M. Al-Nozha, A. Al-Khadra, M. R. Arafah et al., "Metabolic syndrome in Saudi Arabia," Saudi Medical Journal, vol. 26, no. 12, pp. 1918-1925, 2005.

[78] M. M. Al-Nozha, M. A. Al-Maatouq, Y. Y. Al-Mazrou et al., "Diabetes mellitus in Saudi Arabia," Saudi Medical Journal, vol. 25, no. 11, pp. 1603-1610, 2004.

[79] M. Moradi-Lakeh, C. El Bcheraoui, M. Tuffaha et al., "Tobacco consumption in the Kingdom of Saudi Arabia, 2013: findings from a national survey Health promotion and society," $B M C$ Public Health, vol. 151, article 611, 2015.

[80] G. A. Wells, B. Shea, D. O'Connell et al., The NewcastleOttawa Scale (NOS) for Assessing the Quality of Non Randomised Studies in Meta-analyses, Hospital Research Institute, Ottawa, Canada, 2012, http://www.ohri.ca/programs/ clinical_epidemiology/oxford.asp.

[81] M. Badran and I. Laher, "Obesity in arabic-speaking countries," Journal of Obesity, vol. 2011, Article ID 686430, 9 pages, 2011.

[82] A. A. Hedley, C. L. Ogden, C. L. Johnson, M. D. Carroll, L. R. Curtin, and K. M. Flegal, "Prevalence of overweight and obesity among US children, adolescents, and adults, 1999-2002," The Journal of the American Medical Association, vol. 291, no. 23, pp. 2847-2850, 2004.

[83] S. Sanon, R. Patel, C. Eshelbrenner et al., "Acute coronary syndrome in patients with diabetes mellitus: perspectives of an interventional cardiologist," The American Journal of Cardiology, vol. 110, no. 9, supplement, pp. 13B-23B, 2012.

[84] D. J. Angiolillo, M. Roffi, and A. Fernandez-Ortiz, "Tackling the thrombotic burden in patients with acute coronary syndrome and diabetes mellitus," Expert Review of Cardiovascular Therapy, vol. 9, no. 6, pp. 697-710, 2011.

[85] A. Majeed, A. A. El-Sayed, T. Khoja, R. Alshamsan, C. Millett, and S. Rawaf, "Diabetes in the Middle-East and North Africa: an update," Diabetes Research and Clinical Practice, vol. 103, no. 2, pp. 218-222, 2014.

[86] N. S. Alharbi, R. Almutari, S. Jones, N. Al-Daghri, K. Khunti, and S. De Lusignan, "Trends in the prevalence of type 2 diabetes mellitus and obesity in the Arabian Gulf States: systematic review and meta-analysis," Diabetes Research \& Clinical Practice, vol. 106, no. 2, pp. e30-e33, 2014.

[87] F. Daoud, C. El Bcheraoui, M. Tuffaha et al., "The health status of Saudi women: findings from a national survey," Journal of Public Health: Oxford Journals, 2015.

[88] IDF. IDF Middle East and North Africa Region, 2015, http://www.idf.org/membership/mena/saudi-arabia.

[89] T. Kulie, A. Slattengren, J. Redmer, H. Counts, A. Eglash, and S. Schrager, "Obesity and women's health: an evidence-based review," Journal of the American Board of Family Medicine, vol. 24, no. 1, pp. 75-85, 2011.

[90] A. Tailakh, L. S. Evangelista, J. C. Mentes, N. A. Pike, L. R. Phillips, and D. E. Morisky, "Hypertension prevalence, awareness, and control in Arab countries: a systematic review," Nursing \& Health Sciences, vol. 16, no. 1, pp. 126-130, 2014.

[91] P. M. Kearney, M. Whelton, K. Reynolds, P. K. Whelton, and J. He, "Worldwide prevalence of hypertension: a systematic review," Journal of Hypertension, vol. 22, no. 1, pp. 11-19, 2004.

[92] World Health Organization, "Interventions on diet and physical activity: what works: summary report 2009," 2009, http://www. who.int/dietphysicalactivity/summary-report-09.pdf. 
[93] D. Kahan, "Adult physical inactivity prevalence in the Muslim world: analysis of 38 countries," Preventive Medicine Reports, vol. 2, pp. 71-75, 2015.

[94] M. M. Bassiony, “Smoking in Saudi Arabia," Saudi Medical Journal, vol. 30, no. 7, pp. 876-881, 2009.

[95] E. A. Akl, S. K. Gunukula, S. Aleem et al., "The prevalence of waterpipe tobacco smoking among the general and specific populations: a systematic review," BMC Public Health, vol. 11, article 244, 2011.

[96] R. H. Eckel, S. M. Grundy, and P. Z. Zimmet, "The metabolic syndrome," The Lancet, vol. 365, no. 9468, pp. 1415-1428, 2005.

[97] R. M. Mabry, M. M. Reeves, E. G. Eakin, and N. Owen, “Gender differences in prevalence of the metabolic syndrome in Gulf Cooperation Council Countries: a systematic review," Diabetic Medicine, vol. 27, no. 5, pp. 593-597, 2010.

[98] C. El Bcheraoui, M. Tuffaha, F. Daoud et al., "Low uptake of periodic health examinations in the Kingdom of Saudi Arabia, 2013," Journal of Family Medicine and Primary Care, vol. 4, no. 3, pp. 342-346, 2015.

[99] H. Al-Ahmadi, "Challenges facing women leaders in Saudi Arabia," Human Resource Development International, vol. 14, no. 2, pp. 149-166, 2011. 


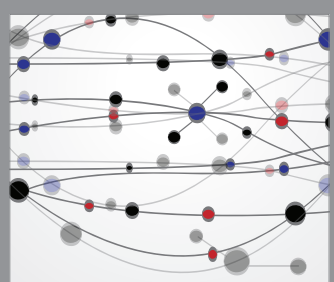

The Scientific World Journal
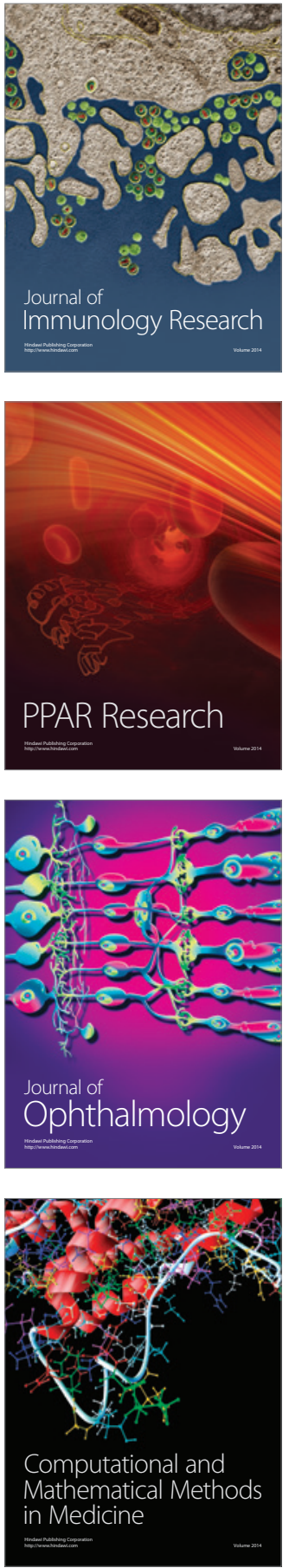

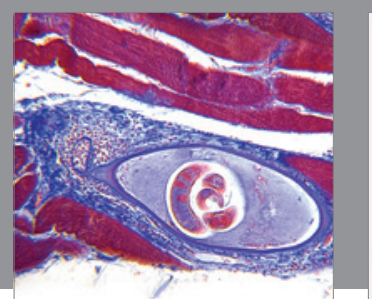

Gastroenterology Research and Practice

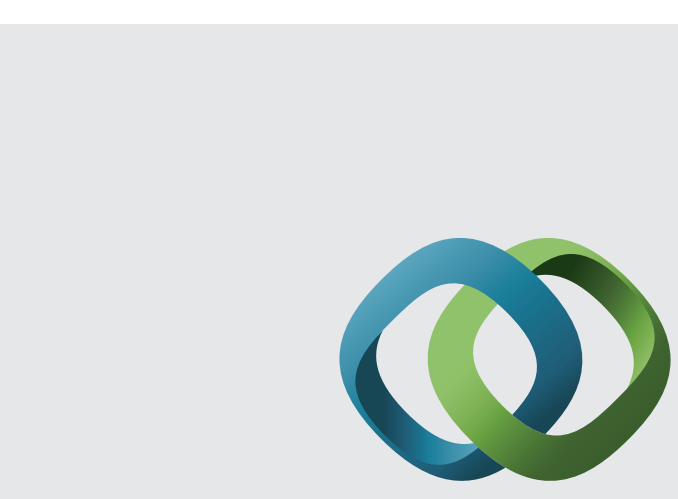

\section{Hindawi}

Submit your manuscripts at

http://www.hindawi.com
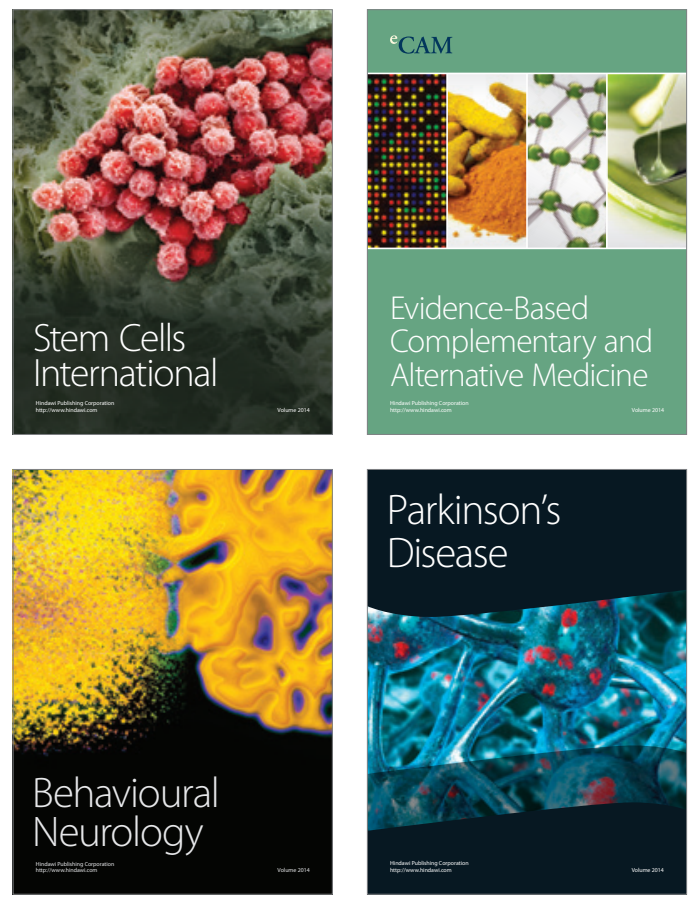
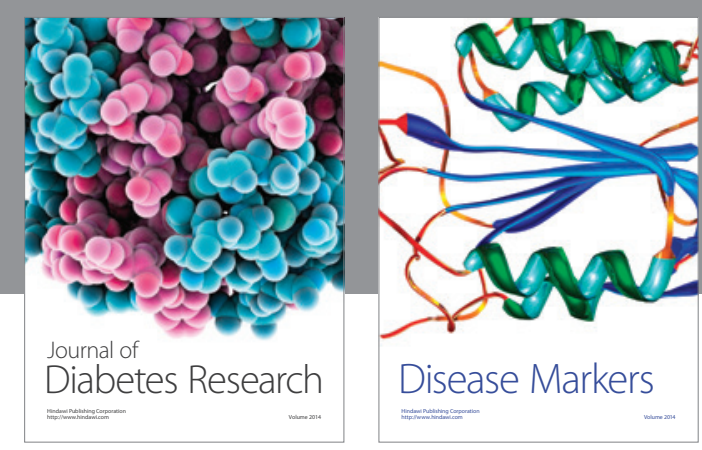

Disease Markers
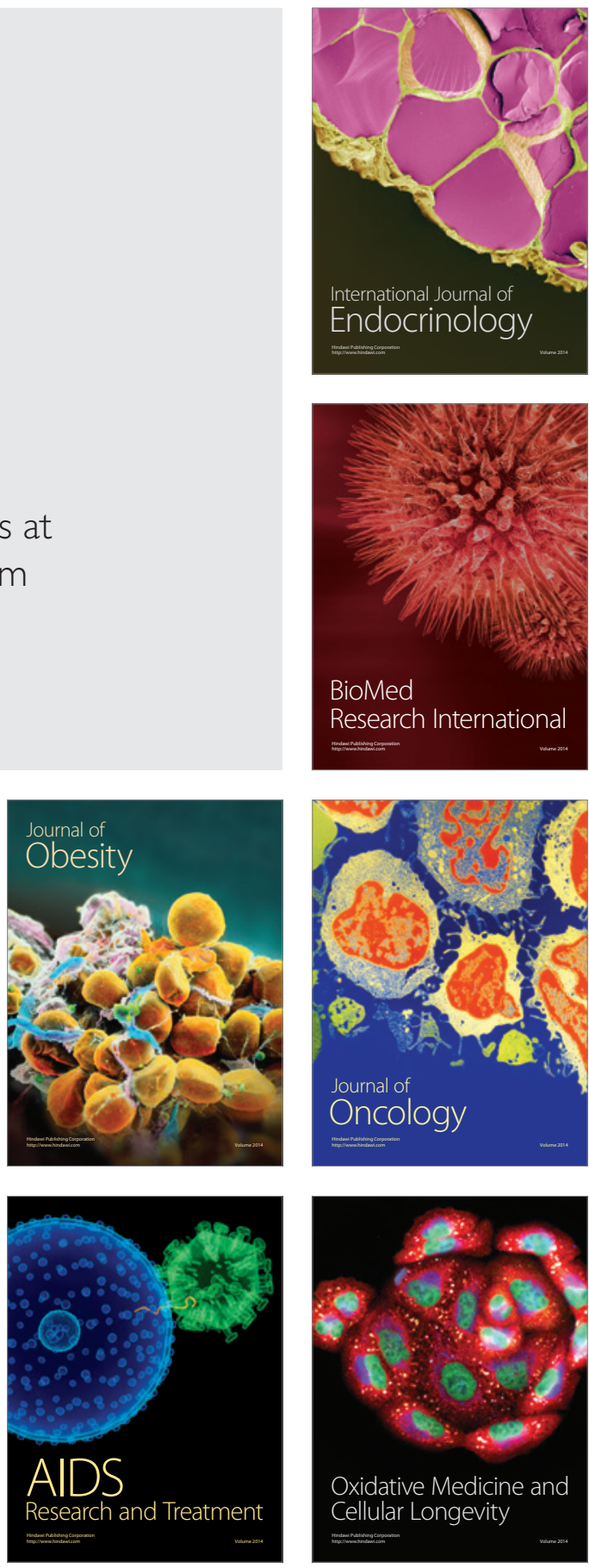